\title{
Physician-Elder Interaction in Community Family Practice
}

\author{
Edward J. Callahan, PhD, Kurt C. Stange, MD, PhD, Stephen J. Zyzanski, PhD, \\ Meredith A. Goodwin, MS, Susan A. Flocke, PhD, and Klea D. Bertakis, MD, MPH
}

Objective: To determine whether outpatient visits by elders seeing community family physicians differ in length or content from visits by younger patients; socioemotional preferences predict visit content; and satisfaction correlates with visit content differentially across age.

Methods: In a multimethod cross-sectional study of 84 community family practices in northeastern Ohio, 3453 adult patient visits with 138 community family physicians were observed; 2362 of these patients completed self-report questionnaires. Three age groups were compared: 18 to 64,65 to 74 , and over 74 years. Length and content of the physician-patient encounter was determined using the Davis Observation Code (DOC); satisfaction was assessed using the MOS 9-item Visit Rating Scale.

Results: Controlling for reason for visit and demographics, visit length averaged 10.7 minutes for each group. Visit content differed significantly on 13 of 20 DOC codes between one of the older groups and the younger group; in 4 instances, content varied between the 2 older groups. Although visit content varied as predicted by socioemotional theory, no consistent patterns of association between visit content and satisfaction emerged.

Discussion: Older patient visits differ from those of younger patients as might be predicted by socioemotional selectivity theory; however, there was little association of visit content with patient satisfaction. (J Am Board Fam Pract 2004;17:19-25.)

Medical breakthroughs during the 1900s have reduced early life mortality drastically and helped to swell the ranks of older people in this nation. ${ }^{1}$ Concerns about access to and quality of primary care for elders are growing as the numbers of people over 65 expands at an unprecedented rate. ${ }^{2,3}$ The definition of what constitutes optimal primary care for older patients, however, remains unclear.

Some data suggest that the primary care visit is different for older patients than for those who are younger. ${ }^{3-7}$ Differences may stem from many fac-

Submitted, revised, 24 March 2003.

From the Department of Family and Community Medicine (EJC, KDB), Center for Health Services Research in Primary Care, University of California, Davis (EJC, KDB); Departments of Family Practice (KCS, SJZ, MAG, SAF), Biostatistics and Epidemiology (KCS, SJZ, MAG), and Sociology (KCS, SJZ), University Hospitals of Cleveland; and Case Western Reserve University Ireland Cancer Center (KCS, SJZ, SAF), Case Western Reserve School of Medicine, Cleveland, Ohio. Address correspondence to Edward J. Callahan, PhD, Department of Family and Community Medicine, University of California, Davis, 4860 "Y" Street, Sacramento, CA 95817 (e-mail: ejcallahan@ucdavis.edu).

This study was supported by grants 1R01-CA80862 and 2R01-CA80862 from the National Cancer Institute, a Generalist Physician Faculty Scholar Award from the Robert Wood Johnson Foundation, and a Family Practice Research Center Grant from the American Academy of Family Physicians. tors, including greater numbers of problems treated, ${ }^{4}$ poorer health status among older patients, ${ }^{5}$ and different preferences for content of interaction. ${ }^{8}$ Greene and her colleagues ${ }^{7}$ identified lower levels of psychosocial content in the visits of older patients and found that older patients agree with their primary care physician about the purpose of the visit less than do younger patients. ${ }^{6}$ It is not clear whether the different content occurs because of different preferences on the part of older patients or reflects different approaches to care by physicians when facing older patients. Regardless, older patients generally report higher satisfaction with care than their younger counterparts. ${ }^{5,9,10}$ This is paradoxical because lower health status, as seen in elders, is usually associated with both different visit content ${ }^{11,12}$ and lower satisfaction. ${ }^{11,13}$

Early research found older patients had shorter visits than younger patients in all medical specialties. ${ }^{14}$ Even after controlling multiple confounders, the same relationship emerged again, except that, among family physicians, the trend toward shorter visits for older patients did not reach significance. ${ }^{15}$ However, in a more recent study observing family practice and internal medicine residents, Callahan et $\mathrm{al}^{5}$ found that older patients had significantly 
longer initial visits than younger patients. In addition to longer visits, elders were found to have a different visit content, including more chatting but less counseling, disease prevention, and health education. Because only initial visits were studied and because residents in training rather than community physicians provided care, it is not clear whether longer visits and different content would be found in a sample of return visits of older patients seeing community family physicians.

Differences in visit content between older and younger patients may result from differences in preferences. Carstensen and her colleagues ${ }^{8}$ theorize that as people age, their preferred interactions change. They argue that as time left in life shortens, preference for the content of interactions shifts from gaining information to regulating emotion. If this is so, physicians might learn to interact differently with older patients. Elder preferences might be apparent in both different visit content and in higher correlation of visit satisfaction with emotion-regulating elements of the physicianpatient interaction over information sharing tasks.

Therefore, we studied 3453 adult outpatient visits to 138 community-based family physicians to test 3 hypotheses: (1) primary care visits are longer for older patients than for younger patients; (2) visits for older patients have a different content than visits for younger patients, as predicted by socioemotional selectivity theory; and (3) there are systematic differences in the association of satisfaction with visit content for different age groups, in which older patients show greater preference for content involving emotional regulation and lower preference for content focused on information processing.

\section{Methods}

\section{Study Design and Data Collection}

These data were gathered in the Direct Observation of Primary Care (DOPC) Study, a crosssectional study of the content of outpatient visits to family physicians practicing in northeastern Ohio. The methods of the DOPC study have been described in detail previously. ${ }^{16,17}$ Briefly, participating physicians providing outpatient care were visited by a team of research nurses; the patient sample was drawn from consecutive visits over 2 days of observation. Patients were informed about the study in the waiting room before seeing their physicians and were enrolled if they gave verbal informed consent.

Research nurses collected data on the content and context of the outpatient visit, including direct observation of the patient visit using the Davis Observation Code $^{18}$ and a patient exit questionnaire containing the MOS 9-item Visit Rating Form as a measure of patient satisfaction. ${ }^{19}$

\section{Sample Selection}

Analyses of time use in the patient visit included all 3453 adult patients (18 years or older) observed in visits. To test hypotheses 1 and 2, patients were grouped into 3 categories by age: 2529 aged 18 to 64 comprised the youngest patient group; 520 aged 65 to 74 made up the older patient group; and 404 aged 75 and older comprised the oldest patient group. Testing hypothesis 3 involved use of satisfaction data from the patient exit questionnaire completed by 2362 adults after the visit: 1738 aged 18 to 64 (youngest patients); 371 aged 65 to 74 (older patients); and 253 aged 75 and older (oldest patients). Analyses of self-reported satisfaction were conducted with 2306 patients who completed all items used to control for potential confounding factors.

\section{Measures}

Davis Observation Code

Nurse observers used direct observation to record visit characteristics. Time use during the visit was measured with the Davis Observation Code (DOC), which categorizes successive 15-second intervals by noting the occurrence or nonoccurrence of 20 operationally defined behavioral categories. ${ }^{18}$

\section{Demographics}

Research nurses reviewed medical records to gather data on patient characteristics including age, gender, whether this was a new or established visit, and number of visits to the physician and the practice within the previous year. Health status was approximated by extracting the number of illnesses identified in the chart.

\section{Patient Exit Questionnaires}

The 4 physician-specific items from the MOS 9-item Visit Rating Form that address satisfaction 


\begin{tabular}{|c|c|c|c|c|}
\hline & $\begin{array}{c}\text { Younger Patients } \\
18-64 \\
(\mathrm{n}=2529)\end{array}$ & $\begin{array}{c}\text { Older Patients } \\
65-74 \\
(\mathrm{n}=520)\end{array}$ & $\begin{array}{c}\text { Oldest Patients } \\
\quad \geq 75 \\
(\mathrm{n}=404)\end{array}$ & $P$ \\
\hline Patient age & 41.8 & 69.5 & 81.3 & $<0.001^{*}$ \\
\hline Patient gender ( $\%$ female) & 64.9 & 60.6 & 65.7 & 0.151 \\
\hline Patient race (\% non-white) & 15.2 & 8.5 & 7.7 & $<0.001^{\text {tł }}$ \\
\hline New vs established patient (\% new) & 10.2 & 4.4 & 3.2 & $<0.001^{\text {tf }}$ \\
\hline \multicolumn{5}{|l|}{ Reason for visit (\%) } \\
\hline Acute illness & 59.5 & 43.8 & 43.1 & $<0.001^{\dagger \ddagger}$ \\
\hline Chronic illness & 21.7 & 41.9 & 47.3 & \\
\hline Well care & 10.3 & 9.8 & 6.2 & \\
\hline Other & 8.6 & 4.4 & 3.5 & \\
\hline Number of visits in previous year & 4.0 & 4.9 & 5.6 & $<0.001^{*}$ \\
\hline Years as patient of physician & 5.2 & 8.2 & 8.2 & $<0.001^{\text {tł }}$ \\
\hline Number of chronic illnesses & 2.1 & 4.2 & 5.0 & $<0.001^{*}$ \\
\hline Completed patient exit questionnaire (\%) & 74.6 & 84.8 & 81.9 & $<0.001^{\dagger+}$ \\
\hline Satisfaction with physician $(1=$ poor, $5=$ excellent $)$ & 4.4 & 4.6 & 4.5 & $<0.001^{\dagger}$ \\
\hline
\end{tabular}

* All three columns differ, $P<.05$.

${ }^{\dagger}$ Column 1 differs from column $2, P<.05$.

${ }^{\ddagger}$ Column 1 differs from column $3, P<.05$.

with physician were scored as a subscale for this study (Cronbach $\alpha=0.90$ ).

\section{Analysis}

Descriptive statistics on the characteristics of patients, visits, and physicians in the sample were calculated. Differences in time use during visits were analyzed by comparing the mean proportion of time spent on each activity between the 3 groups using analysis of variance and the Benjamini-Hochberg modified Bonferroni procedure to correct for multiple hypothesis testing. ${ }^{20}$ These analyses were adjusted for patient characteristics distributed differently among age groups. Duncan's multiple comparison procedure was used to identify pairwise differences among activities for which time was significantly associated with age group. Finally, partial correlations were computed between time spent on behavior and patient satisfaction adjusting for confounding variables that related to personal satisfaction and differed among age groups. Adjusting for confounding variables results in slightly lower numbers of patients in Tables 2 and 3 because some patients are excluded for missing data on a measure being controlled.

\section{Results}

Table 1 presents patient information on the 3 groups contrasted in direct observation. The 2 older groups contained fewer minority group members. The number of visits during the prior year increased significantly for each successive age group, as did the reported mean length of relationship with physician. Number of chronic illnesses increased with age; youngest patients reported different reasons for their visits, being much less likely to visit for chronic conditions. Youngest patients also reported significantly less satisfaction with their physicians than older patients.

Length of the visit and the proportion of the visit during which each of 20 coded behaviors occurred across groups are presented in Table 2. Means are adjusted for patient gender and race, reason for visit, number of visits in the prior year, number of chronic illnesses, status as a new or established patient, and the number of years as a patient of the physician. The average length of visit was similar for the 3 age categories, averaging 10.7 minutes. Significant differences between pairs of groups were found for 13 of 20 content categories after accounting for multiple hypothesis testing. Decreases were observed in proportion of visit used for planning treatment, health education, family information, counseling, exercise advice, smoking discussion, health promotion, and discussion of substance use. Increases were observed in proportion of visit used for chatting, physical examination, patient questions, and compliance assessment. 
Table 2. Comparison of Time Use across Age Categories*

\begin{tabular}{|c|c|c|c|c|}
\hline & $\begin{array}{c}\text { Younger Patients } \\
18-64 \\
(\mathrm{n}=2469)\end{array}$ & $\begin{array}{c}\text { Older Patients } \\
\quad 65-74 \\
(\mathrm{n}=513)\end{array}$ & $\begin{array}{l}\text { Oldest Patients } \\
\quad \geq 75 \\
(\mathrm{n}=395)\end{array}$ & $P$ \\
\hline History taking & 57.3 & 58.7 & 57.3 & 0.31 \\
\hline Planning treatment & 32.5 & 31.3 & 29.9 & $0.007^{\dagger}$ \\
\hline Physical examination & 20.9 & 22.1 & 22.9 & $0.02^{\dagger}$ \\
\hline Health education & 19.9 & 18.2 & 16.6 & $<0.001^{\ddagger}$ \\
\hline Feedback on evaluation results & 13.4 & 14.6 & 14.7 & $0.01 \S^{\dagger}$ \\
\hline Family information & 10.4 & 8.5 & 8.5 & $<0.001^{\text {\$十 }}$ \\
\hline Chatting & 7.0 & 8.2 & 10.1 & $<0.001^{\ddagger}$ \\
\hline Structuring the interaction & 7.6 & 8.1 & 8.5 & 0.11 \\
\hline Patient questions & 6.6 & 7.5 & 8.1 & $<0.001^{\$ \dagger}$ \\
\hline Preventive services & 3.0 & 3.6 & 3.1 & 0.16 \\
\hline Procedures & 2.6 & 2.0 & 2.7 & 0.56 \\
\hline Nutrition advice & 2.2 & 2.2 & 1.6 & 0.05 \\
\hline Counseling & 2.4 & 1.6 & 1.1 & $0.001^{\S+}$ \\
\hline Exercise advice & 2.0 & 2.0 & 1.2 & $0.005^{+\|}$ \\
\hline Compliance assessment & 1.6 & 2.1 & 2.1 & $0.001^{\S \dagger}$ \\
\hline Smoking behavior assessment or advice & 1.9 & 0.9 & 0.4 & $<0.001^{\ddagger}$ \\
\hline Assessing patient's health knowledge & 1.4 & 1.3 & 1.0 & 0.06 \\
\hline Health promotion & 1.7 & 1.1 & 0.8 & $<0.001^{\text {\$十 }}$ \\
\hline Negotiation & 1.1 & 1.3 & 1.4 & 0.15 \\
\hline Substance use assessment or advice & 0.6 & 0.2 & 0.2 & $<0.001^{\S \dagger}$ \\
\hline Length of visit & 10.7 & 10.7 & 10.7 & 0.99 \\
\hline
\end{tabular}

* Analyses are adjusted for patient sex, race, reason for visit, number of visits in previous year, number of chronic illnesses, new or established patient, and number of years as patient of physician.

${ }^{\dagger}$ Column 1 differs from column $3, P<.05$.

${ }^{\ddagger}$ All three columns differ, $P<.05$.

$\$$ Column 1 differs from column $2, P<.05$.

" Column 2 differs from column $3, P<.05$.

Each behavioral category was then correlated with patient satisfaction for each age-group. Table 3 presents the correlations between the proportion of the visit in which each behavioral category occurred and patient satisfaction with the physician. Because of the difference in sample size between the 3 groups, the minimum partial correlation considered significantly different from zero differs for each. A partial correlation greater than 0.047, 0.103 , and 0.126 is significant at the $P<.05$ level for the youngest patients, older patients, and oldest patients, respectively.

Nine DOC codes showed significantly different levels of correlation with satisfaction across age groups: planning treatment, physical examination, health education, family information, structuring the interaction, counseling, exercise discussion, compliance assessment, and discussion of substance use. Three behaviors differed between the older and oldest patient groups: planning treatment and health education were positively associated with satisfaction for the older patients whereas family information was negatively associated. In addition, younger patients showed a stronger correlation of satisfaction with length of visit than did the oldest patients.

\section{Discussion}

The primary care visit of older patients is clearly different from visits of younger patients. Although more chronic illnesses and more frequent visits were found for older patients, differences in the content of the visit persisted even after number of illnesses, reason for visit and demographic variables were controlled. Older patients in this study reported higher satisfaction with care, a finding consistent with prior reports ${ }^{5,9,10}$ but still remarkable because lower health status ordinarily predicts lower satisfaction. ${ }^{11-13}$ 
Table 3. Partial Correlation of Percentage of Time Spent on Behavior with Satisfaction with Physician*

\begin{tabular}{|c|c|c|c|}
\hline & $\begin{array}{c}\text { Younger Patients } \\
18-64 \\
(\mathrm{n}=1711)\end{array}$ & $\begin{array}{l}\text { Older Patients } \\
\quad 65-74 \\
(\mathrm{n}=356)\end{array}$ & $\begin{array}{c}\text { Oldest Patients } \\
\geq 75 \\
(\mathrm{n}=239)\end{array}$ \\
\hline History taking & -0.041 & 0.002 & -0.082 \\
\hline Planning treatment ${ }^{\dagger}$ & -0.037 & -0.166 & 0.160 \\
\hline Physical examination $^{\ddagger}$ & -0.052 & -0.022 & 0.080 \\
\hline Health education ${ }^{\neq \S}$ & 0.004 & -0.035 & 0.143 \\
\hline Feedback on evaluation results & -0.055 & -0.025 & 0.038 \\
\hline Family information ${ }^{\neq \S}$ & 0.045 & 0.061 & -0.102 \\
\hline Chatting & 0.067 & 0.142 & 0.068 \\
\hline Structuring the interaction ${ }^{\neq}$ & -0.061 & -0.056 & 0.082 \\
\hline Patient questions & -0.027 & -0.118 & -0.032 \\
\hline Preventive services & 0.011 & 0.015 & 0.066 \\
\hline Procedures & 0.051 & 0.060 & 0.021 \\
\hline Nutrition advice & 0.038 & 0.049 & -0.044 \\
\hline Counseling $^{\ddagger}$ & 0.027 & -0.047 & -0.107 \\
\hline Exercise advice & -0.008 & 0.066 & 0.006 \\
\hline Compliance assessment $^{\ddagger}$ & 0.029 & -0.016 & -0.107 \\
\hline Smoking behavior assessment or advice & 0.035 & 0.008 & -0.034 \\
\hline Assessing patient's health knowledge & 0.036 & -0.044 & -0.067 \\
\hline Health promotion & 0.028 & -0.033 & -0.017 \\
\hline Negotiation & -0.028 & -0.021 & 0.051 \\
\hline Substance use assessment or advice ${ }^{\|}$ & 0.009 & -0.116 & 0.002 \\
\hline Length of visit ${ }^{\ddagger}$ & 0.151 & 0.099 & 0.019 \\
\hline
\end{tabular}

* Partial correlation is the magnitude of correlation that is significantly different from $0(P<.05)$ is $0.047,0.103$, and 0.126 for the younger, older, and oldest patients, respectively. Analyses are adjusted for patient gender, reason for visit, chronic illnesses and number of visits in previous year.

${ }^{\dagger}$ All three columns differ, $P<.05$.

${ }^{\ddagger}$ Column 1 differs from column $3, P<.05$.

$\$$ Column 2 differs from column $3, P<.05$.

" Column 1 differs from column $2, P<.05$.

Support was strong for the second hypothesis, mixed for the third, and absent for the first. After controlling for relevant confounding variables, visits were not found to be longer for older patients, as predicted in hypothesis 1 . The lack of difference in visit length contrasts with 2 earlier studies ${ }^{14,15}$ that found shorter visits for older patients and one study that found longer visits for older patients. ${ }^{5}$ The only study to find longer visits for older patients studied only initial visits, ${ }^{5}$ with results that do not seem to generalize to return visits. The equivalence of visit length across age groups, after reason for visit is controlled, is perhaps as surprising as the brevity of the average visit for each.

Support was strong for the second hypothesis, however, that content of visits for older patients was different from content for younger patients. In this study of visits with community physicians, there were significant differences between visits for older and younger patients in 13 of the 20 DOC codes. In 8 of 13 cases, the difference expanded further in the oldest group, suggesting that aging continues to change the physician-patient interaction in a dose-response fashion.

Physicians were observed to act in ways consistent with the socioemotional selectivity theory of Carstensen et $\mathrm{al}^{8}$ in several instances. This theory suggests that, as people age, socioemotional regulation is valued more but gaining information is valued less. Of behaviors assumed to be related to emotional regulation, chatting and question-asking increased whereas counseling decreased. Of behaviors associated with imparting information, health education, health promotion, and exercise discussion decreased whereas evaluation feedback increased and discussion of nutrition remained stable. Thus, 5 of 8 behaviors changed in directions consistent with socioemotional theory, whereas one remained stable and 2 moved in contradictory directions. 
Counseling might be expected to increase by socioemotional theory because it would presumably help regulate emotion. However, both this and a prior study ${ }^{5}$ found less counseling for older patients. Several factors, including age discrepancy between physician and patient, may contribute to this finding. Although community physicians studied here (mean age 42) were closer in age to the older patients than were the family medicine residents in the study by Callahan et $\mathrm{al}^{5}{ }^{5}$ older patients still encountered physicians who were both younger and members of a different birth cohort. These differences may contribute to avoidance of counseling and other psychosocial issues. ${ }^{21}$ Older patients in this study also represent the last "prepsychological" generation in the United States and may avoid discussion of personal issues. ${ }^{22}$ Failure to discuss psychosocial issues may contribute to difficulties in identifying depression among older patients. $^{23,24}$

Patient preferences are probably involved here: when counseling did occur, it correlated negatively with satisfaction for older patients. Patient question-asking increased with age, however, perhaps reflecting an effort to gain immediate reassurance and emotional support. Counseling, on the other hand, often requires enduring immediate emotional discomfort in pursuit of longer-term adjustment. Only study of later cohorts of elders will reveal whether avoidance of counseling is associated with the aging process itself or simply reflects preferences of the current birth cohort of elders.

Use of time for efforts to change health behavior declined fairly consistently with age, as might be predicted by socioemotional theory: less of the visit was spent on health education, health promotion, and discussion of exercise, smoking, and use of substances. Time use for many of the technical aspects of the visit was greater for older patients (physical examination, evaluation feedback, and assessment of compliance), a finding consistent with treatment of more illness. Although socioemotional theory might predict less evaluation feedback because it involves giving information, the number of laboratory tests and other findings require more feedback to the patient facing more illness, regardless of patient preferences.

Decreases in efforts around health behavior change and disease prevention may also reflect recognition of decreasing time left in life and a shifting in the goals of primary care on the part of the physician. The family physician may see younger patients as more appropriate targets for health promotion and disease prevention. In turn, experienced clinicians may alter their treatment goals with older patients, especially as health status declines and the imminence of death increases. ${ }^{25}$

Although physicians are acting in ways consistent with socioemotional selectivity theory, Table 3 shows little evidence of age effecting a monotonic change in the association of visit content with patient satisfaction. Thus, there was little support for our third hypothesis. Correlations between visit content and patient satisfaction were small and did not differ among the 3 groups in a linear way. This may be because of the very limited range in patient satisfaction among older patients who tend to uniformly report high satisfaction. Perhaps this cohort of older patients holds all physicians and medicine itself in high esteem, thus clouding the relationship of discreet behavioral codes with satisfaction. The greater satisfaction reported by older patients may reflect the membership in that birth cohort and shared valuing of physicians rather than reflecting an impact of aging. Only repeated monitoring of this phenomenon with future aging cohorts can answer this question.

One limitation to this study was that not all observed patients completed questionnaires. Nonresponse was more strongly associated with being younger and being a new patient. Even so, the nonresponses among older patients may have limited the variability of the satisfaction measure and slightly biased the study toward the null hypothesis.

This study has helped provide further information on how patient aging influences the content of the primary care visit. There is evidence here that the older patient elicits, and perhaps values, a different kind of visit, perhaps with more emphasis on emotional connection to the physician and less emphasis on information giving as the amount of time in life decreases. These kinds of visits can be provided with no loss in quality of care.

\section{References}

1. Editors. Looking back on the millennium in medicine. N Engl J Med 2000;342:42-9.

2. Beisecker AE. Older persons' medical encounters and their outcome. Res Aging 1996;18:9-31.

3. Hess BB. Growing old in America in the 1990s. In: Hess BB, Markson EW, editors. Growing old in America 1991, 4th ed. New Brunswick (NJ): Transaction Publishers. p. 5-22. 
4. Adelman R, Greene MG, Ory MG. Communication between older patients and their physicians. Clin Geriatr Med 2000;16:1-24.

5. Callahan EJ, Bertakis KD, Azari R, Robbins JA, Helms LJ, Chang DW. The influence of patient age on primary care physician-patient interaction. J Am Geriatr Soc 2000;48:30-5.

6. Greene MG, Adelman RD, Charon R, et al. Concordance between physicians and their older and younger patients in the primary care medical encounter. Gerontologist 1989;29:809-13.

7. Greene MG, Hoffman S, Charon R, Adelman RD. Psychosocial concerns in the medical encounter: a comparison of the interactions of doctors with their old and young patients. Gerontologist 1987;27: 164-8.

8. Carstensen LL, Isaacowitz DM, Charles ST. Taking time seriously. A theory of socioemotional selectivity. Am Psychol 1999;54:165-81.

9. Breemhaar B, Vissar AP, Kleunen JGVM. Perceptions and behaviour among elderly hospital patients: Description and explanation of age differences in satisfaction, knowledge, emotions and behavior. Soc Sci Med 1990;31:1377-85.

10. Greene MG, Adelman RD, Friedmann E, Charon R. Older patient satisfaction with communication during an initial patient encounter. Soc Sci Med 1994; 38:1279-88.

11. Bertakis KD, Callahan EJ, Helms LJ, Azari R, Robbins JA. The effect of patient health status on physician practice style. Fam Med 1993;25:530-5.

12. Hall JA, Roter DL, Milburn MA, Daltroy LH. Patients' health as a predictor of physician and patient behavior in medical visits. A synthesis of four studies. Med Care 1996;34:1205-18.

13. Hall JA, Milburn MA, Roter DL, Daltroy LH. Why are sicker patients less satisfied with their medical care? Tests of two explanatory models. Health Psychol 1998;17:70-5.

14. Keeler EB, Solomon DH, Beck JC, Mendenhall RC,
Kane RL. Effect of patient age on duration of medical encounters with physicians. Med Care 1982;20: 1101-8.

15. Radecki SE, Kane RL, Solomon DH, Mendenhall RC, Beck JC. Do physicians spend less time with older patients? J Am Gerontol Soc 1988;36:713-8.

16. Stange KC, Zyzanski SJ, Smith TF, et al. How valid are medical records and patient questionnaires for physician profiling and health service research? A comparison with direct observation of patient visits. Med Care 1998;36:851-67.

17. Stange KC, Zyzanski SJ, Flocke SA, et al. A description of 4454 patient visits to 138 family physicians in 84 practices. J Fam Pract 1998;46:377-89.

18. Callahan EJ, Bertakis KD. Development and validation of the Davis Observation Code. Fam Med 1991; 23:19-24.

19. Rubin HR, Gandek B, Rogers WH, Kosinski M, McHorney CA, Ware JE Jr. Patients' ratings of outpatient visits in different practice settings. Results from the Medical Outcomes Study. JAMA 1993;270: 835-40.

20. Benjamini Y, Hochberg Y. Controlling the false discovery rate: a practical and powerful approach to multiple testing. J Royal Stat Soc 1995;57:289-300.

21. Roter DL. The outpatient medical encounter and elderly patients. Clin Geriatr Med 2000;16:95-107.

22. Pipher MB. Another country: Navigating the emotional terrain of our elders. New York: Riverhead Books, 1999.

23. Callahan CM, Dittus RS, Tierney WM. Primary care physicians' medical decision making for late-life depression. J Gen Int Med 1996;11:218-25.

24. Callahan EJ, Bertakis KD, Azari R, Helms LJ, Robbins JA, Miller J. Depression in primary care: Patient factors influencing recognition. Fam Med 1997;29: 172-76.

25. Charon R. The seasons of the patient-physician relationship. Clin Geriatr Med 2000;16:37-50. 